\title{
Effect of music on anxiety, stress, and depression levels in patients undergoing coronary angiography
}

F. Moradipanah, ${ }^{1}$ E. Mohammadi ${ }^{1}$ and A.Z. Mohammadil ${ }^{2}$

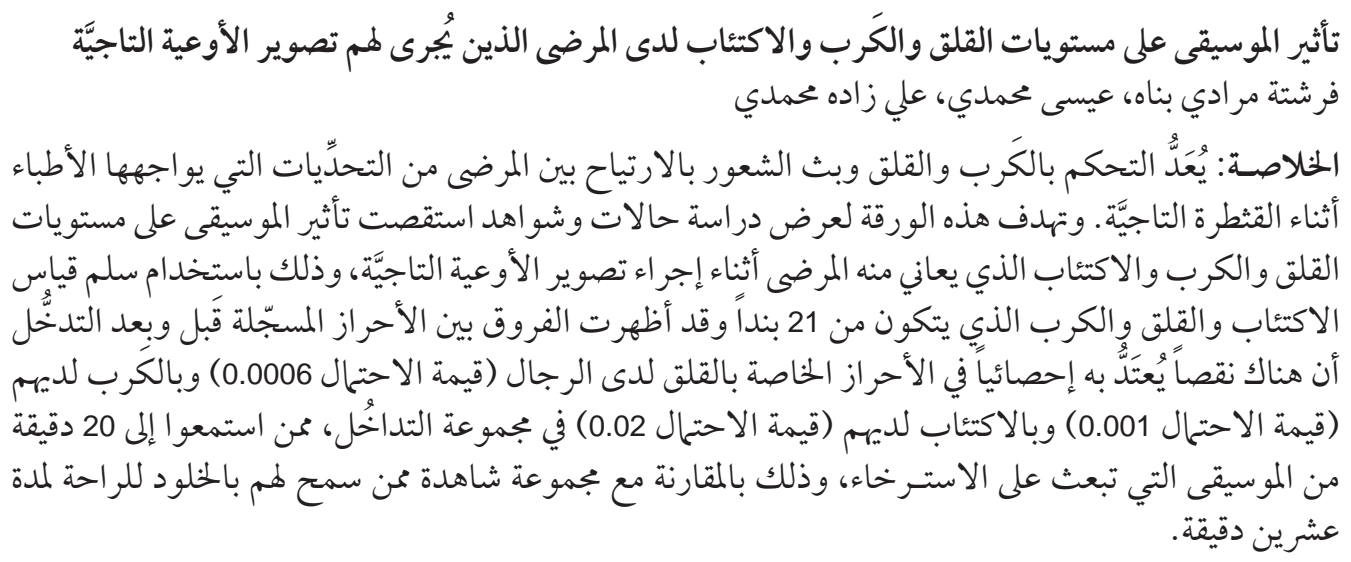

ABSTRACT Control of stress and anxiety and the promotion of comfort are challenges facing health practitioners involved in catheterization. The aim of this case-control study was to examine the effect of music on the levels of anxiety, stress, and depression experienced by patients undergoing coronary angiography, as measured by the 21-item Depression Anxiety Stress Scales. Differences in pre- and post-intervention scores demonstrated that there were significant decreases in mean scores of state anxiety $(P=0.006)$, stress $(P=0.001)$ and depression $P=0.02)$ in the intervention group, who listened to 20 minutes of relaxing music, as compared with the control group who had 20 minutes of bed rest.

Effets de la musique sur les niveaux d'anxiété, de stress et de dépression chez des patients subissant une angiographie coronarienne

RÉSUMÉ Le contrôle du stress et de l'anxiété et les mesures visant à assurer le confort sont des défis que doivent relever les professionnels de la santé concernés par le cathétérisme. L'objectif de cette étude cas/témoins était d'examiner les effets de la musique sur les niveaux d'anxiété, de stress et de dépression ressentis par les patients subissant une angiographie coronarienne, en les mesurant à l'aide de l'échelle DASS (Depression Anxiety Stress Scales) composée de 21 items. Les différences entre les scores avant et après l'intervention ont montré une baisse significative des scores moyens d'anxiété-état $(P=0,006)$, de stress $(P=0,001)$ et de dépression $(P=0,02)$ dans le groupe qui avait écouté une musique relaxante pendant 20 minutes, par rapport au groupe témoin qui était simplement resté alité pendant 20 minutes.

${ }^{1}$ Department of Nursing, Tarbiat Modares University, Tehran, Islamic Republic of Iran (Correspondence to E. Mohammadi:mohamade@modares.ac.ir).

${ }^{2}$ Department of Social Medicine, Shahid Beheshti Medical Sciences University, Tehran, Islamic Republic of Iran. Received: 20/11/06; accepted: 11/01/07

المجلة الصحية لشرق المتوسط، منظمة الصحة العالمية، المجلد الخامس عشر، العدد ب، 9 +. 


\section{Introduction}

Coronary angiography is a common invasive procedure for diagnosis of cardiovascular diseases which can be acutely stressful for many patients [1].

The current study investigated a safe and noninvasive nursing intervention [2] to reduce stress and anxiety in patients undergoing coronary angiography. Art, dance and music therapy are becoming an important part of complementary medicine. These creative arts therapies can contribute to all areas of health care and most psychological and physiological illnesses [3]. Music therapy is the therapeutic use of music and musical activities in the treatment of somatic and mental diseases. In the past few decades it has developed from a quasi-professional working field into an increasingly evidencebased treatment for various diseases [4]. Application of music therapy is based on Rogers' Science of Unitary Human Beings theory [5].

Studies exploring the effectiveness of music therapy have produced different results. Some have indicated that music therapy reduced stress and anxiety in the patients [6-10], but others have found no effect of music intervention on post-procedural pain and anxiety, although music therapy improved the level of comfort in patients $[1,11]$. Gallagher et al. indicated that music therapy is invaluable in palliative medicine [12]. The existing studies are difficult to interpret since some of them provided conflicting results. Furthermore, most of the studies did not examine the levels of anxiety and stress on pre-operative patients, whereas much of the research over the past decades has shown that anxiety and stress levels are raised before surgery.

Therefore, the present study in the Islamic Republic of Iran examined the following question: Do patients undergoing coronary angiography who listen to music for 20 minutes have less stress, anxiety and depression prior to and after angiography than those who do not listen to music?

\section{Methods}

\section{Study design}

This study was a randomized controlled trial with a pre-intervention-post-intervention design with a music therapy intervention group $(n=37)$ and a control group $(n=37)$. The study was conducted as a randomized clinical trial to limit sampling errors. The study was conducted in 2005 .

\section{Sample}

The study sample was patients who were scheduled for coronary angiography at a university hospital in Tehran. Patients who were undergoing angiography and met the inclusion criteria were invited to participate. All participants gave their informed consent prior to entering the study. Patients with the following characteristics were eligible for inclusion in the study: aged 40-60 years; scheduled for angiography for the first time; had no auditory deficits or psychological disorders; able to hear music; able to use a cassette player independently; and interested in listening to music. Using a wristwatch the Tick-Tock test was carried out to diagnose hearing impairments, and psychological disorders were detected by a neurologist. Patients were excluded from the study if they were receiving narcotic analgesics, antidepressants or antianxiety drugs, as these may decrease cognitive ability and inhibit the ability to use a cassette player, thereby diminishing accurate measurement of the independent variable. Furthermore, these drugs reduce stress, anxiety and depression, and might influence the exact measurement of the dependent vari- 
able. Respondents were asked to document the use of analgesic agents administered in conjunction with the procedure.

By using Altman's nomogram, a sample size of 74 (37 patients in each group) was necessary to give the study $90 \%$ power to detect a clinical difference of 3 points with a standard deviation (SD) of 1 in each of the groups. A nonprobability convenience sample of 74 patients was obtained and participants were randomly allocated to the music intervention or control group depending on the admission date for angiography. Patients admitted on even-numbered days were allocated to the music group and patients admitted on odd-numbered days were assigned to the control group. It should also be noted that hospital admissions were offered randomly throughout the days of the week and there was no specific day allotted to certain patients. The nursing staff and the shift work system were not changed during the study period. Admissions to the catheterization laboratory were capped at 4 to 5 patients per day and patients were discharged 24 hours after completion of the procedure.

\section{Data collection}

The short-form of the Depression Anxiety Stress Scales (DASS-21) was used to measure the level of depression, anxiety and stress. DASS is a reliable and valid method of assessing features of depression, anxiety and stress in clinical and nonclinical groups. It includes items that measure symptoms typically associated with dysphoric mood (e.g. sadness or worthlessness). The DASS21 consists of 21 items, 7 in each of the subscales: depression (DASS-21-D), anxiety (DASS-21-A) and stress (DASS-21-S), rated on a 4-point scale from 3 "applied to me very much or most of time" to 0 "did not apply to me". Antony et al.'s estimates of the reliability of the DASS-21 gave Cron- bach alpha scores of $0.94,0.87$ and 0.91 for the depression, anxiety and stress sub-scales respectively [13]. Our computed values of Cronbach alpha were considered adequate with $0.94,0.92$ and 0.89 for depression, anxiety and stress respectively.

The music group was given a tape player and a music cassette which was prearranged by the researcher; all the participants affirmed that they took pleasure from music. The 20-minute tape consisted of 3 relaxing pieces of music: "Canon in D" composed by Johann Pachelbel; the theme from "Love story" played by Richard Clayderman and "Dance of the iguana" by Stevan Pasero. All the 3 pieces of music had $70-80$ beats per minute and were based on slow and steady rhythms. The most relaxing music had a tempo of approximately $60-80$ beats per minute [14]. The tape was played through earphones from a cassette player.

The patients were required to arrive at the hospital at least 1.5 hours before the angiography procedure. Before angiography, all participants completed the preintervention DASS-21. Then participants in the music group were asked to sit in a comfortable bed and avoid any distractions such as reading, speaking on the telephone, listening to the radio or watching television. They were instructed to listen to the 20 minute music tape and then complete the post-intervention DASS-21. Instead of the music intervention, the control group was asked to sit in a relaxed position in a quiet comfortable bed for 20 minutes and avoid distractions including telephones, radio and television; however they were allowed to read newspapers, books or magazines. After 20 minutes of music or 20 minutes of bed rest all participants completed the postintervention DASS-21 before undergoing angiography. After the angiography, all participants repeated the pre-intervention DASS-21 immediately after transferring to

المجلة الصحية لشرق المتوسط، منظمة الصحة العالمية، المجلد الخنامس عشر، العدد ب، 9 +. 
the recovery ward. Then the music group listened to the same music tape and repeated the post-intervention DASS-21, while the control groups had 20 minutes of bed rest before repeating the post-intervention DASS-21.

Patient's stress, depression and anxiety levels might be influenced by sudden changes in haemodynamics and psychological status. Therefore, while participants were receiving needed routine care, any homodynamic and psychological changes affecting the patient's stress, depression and anxiety levels were observed and if there was excessive emotional tension or unpleasant news the patient was excluded from the study.

Because some physicians informed their patients about the angiography results and this could have influenced the level of stress, anxiety and depression, we added a question about whether the patient had received the result of the angiography test, and if so, whether the test result was normal or abnormal.

\section{Ethical considerations}

Ethical approval for the study was obtained from the institutional review board to ensure protection of human subjects. All participants gave written informed prior to their participation.

With respect to patient's confidentiality, numbers were used to identify participants rather than names. Participants were informed that their participation was voluntary, they had the right to withdraw at any time without needing to give a reason and that their care would not be affected whether or not they took part.

\section{Data analysis}

Data were analysed using SPSS, version 11. The independent sample $t$-test and chisquared tests were calculated to determine any significant differences in the demographic distributions of the 2 groups.

For each patient, the pre-intervention score was subtracted from post-intervention score and the mean values of the resulting scores were calculated to verify if these mean values were significantly different between the intervention and control groups. The pre-intervention group mean scores were also compared to the post-intervention group mean scores to determine if there was a difference between the group mean test scores. $t$-tests were conducted to determine whether there was a significant difference between pre- and post-intervention scores of individuals in both groups before and after angiography.

\section{Results}

The difference in the distribution of demographic characteristics between the 2 groups was not statistically significant (Table 1 ). The control and music groups had the same mean age: 50.6 (SD 7.1) years versus 50.6 (SD 5.8) years. There was no significant difference in the sex distribution (15 men and 22 women in the control group and 22 men and 15 women in the music group).

The findings and $t$-test results are summarized in Table 2 for the control and intervention groups before and after angiography. Before angiography, descriptive statistics showed that the pre-intervention mean scores were similar in the music intervention group and the control group for stress [11.35 (SD 4.31) versus 11.00 (SD 4.94)], for anxiety [6.83 (SD 4.14) versus 6.81 (SD 4.29)] and for depression [6.59 (SD 4.55) versus 5.86 (SD 4.19)]. The post-intervention mean scores after the music intervention, however, were lower in the music group than the control group for stress [6.16 (SD 4.98) versus 8.7 (SD 4.89)], 


\begin{tabular}{|c|c|c|c|c|}
\hline \multirow[t]{2}{*}{ Characteristic } & \multicolumn{2}{|c|}{$\begin{array}{l}\text { Control group } \\
\quad(n=37)\end{array}$} & \multicolumn{2}{|c|}{$\begin{array}{l}\text { Intervention group } \\
\qquad(n=37)\end{array}$} \\
\hline & Mean & $S D$ & Mean & $S D$ \\
\hline Age (years) & 50.6 & 7.1 & 50.6 & 5.8 \\
\hline Duration of disease (months) & 15.2 & 15.1 & 12.2 & 14.9 \\
\hline \multirow[t]{2}{*}{ Daily use of music (min/day) } & 49.4 & 62.4 & 69.4 & 80.2 \\
\hline & No. & $\%$ & No. & $\%$ \\
\hline \multicolumn{5}{|l|}{ Sex } \\
\hline Male & 15 & 40.5 & 22 & 59.5 \\
\hline Female & 22 & 59.5 & 15 & 40.5 \\
\hline \multicolumn{5}{|l|}{ Marital status } \\
\hline Married & 330 & 89.2 & 4 & 10.8 \\
\hline Single & 31 & 83.8 & 6 & 16.2 \\
\hline \multicolumn{5}{|l|}{ Literacy } \\
\hline Illiterate & 12 & 32.4 & 12 & 32.4 \\
\hline Diploma and below & 22 & 59.4 & 20 & 54.0 \\
\hline Higher education & 3 & 8.1 & 5 & 13.5 \\
\hline \multicolumn{5}{|l|}{ History of hospitalization } \\
\hline Yes & 29 & 78.4 & 27 & 73.0 \\
\hline No & 8 & 21.6 & 10 & 27.0 \\
\hline
\end{tabular}

Because of rounding, not all percentages total 100. $S D=$ standard deviation.

for anxiety [4.13 (SD 3.81) versus 6.10 (SD 3.71)] and for depression [4.40 (SD 4.42) versus 5.02 (SD 3.79)]. These differences in mean values of pre- to post-intervention changes between both groups before angiography were statistically significant: for stress $(P=0.001)$, for anxiety $(P=$ $0.006)$ and for depression $(P=0.02)$. Anxiety, depression and stress scores among the music group were significantly reduced pre- to post-intervention, while the control group reported about the same level of preintervention and post-intervention stress, anxiety and depression on the DASS- 21 administered before angiography.

After angiography, mean scores for stress, anxiety and depression were lower in both groups and these were similar comparing the music intervention and control groups (Table 2). The results of the $t$-test showed no statistically significant differences between the music and control groups with respect to the changes between preand post-intervention mean scores on the stress $(P=0.14)$, anxiety $(P=0.94)$ and depression $(P=0.48)$ scales.

The data showed no relationship between the demographic characteristics of the groups and the stress, anxiety and depression levels (data not shown).

The results showed that the group that was informed of the angiography results experienced lower stress, anxiety and depression levels than the group that was not informed. There was a significant difference between the informed group and the non-informed group in the mean scores after angiography for stress $(t=-2.4, \mathrm{df}=$ 
La Revue de Santé de la Méditerranée orientale, Vol. 15, N3, 2009

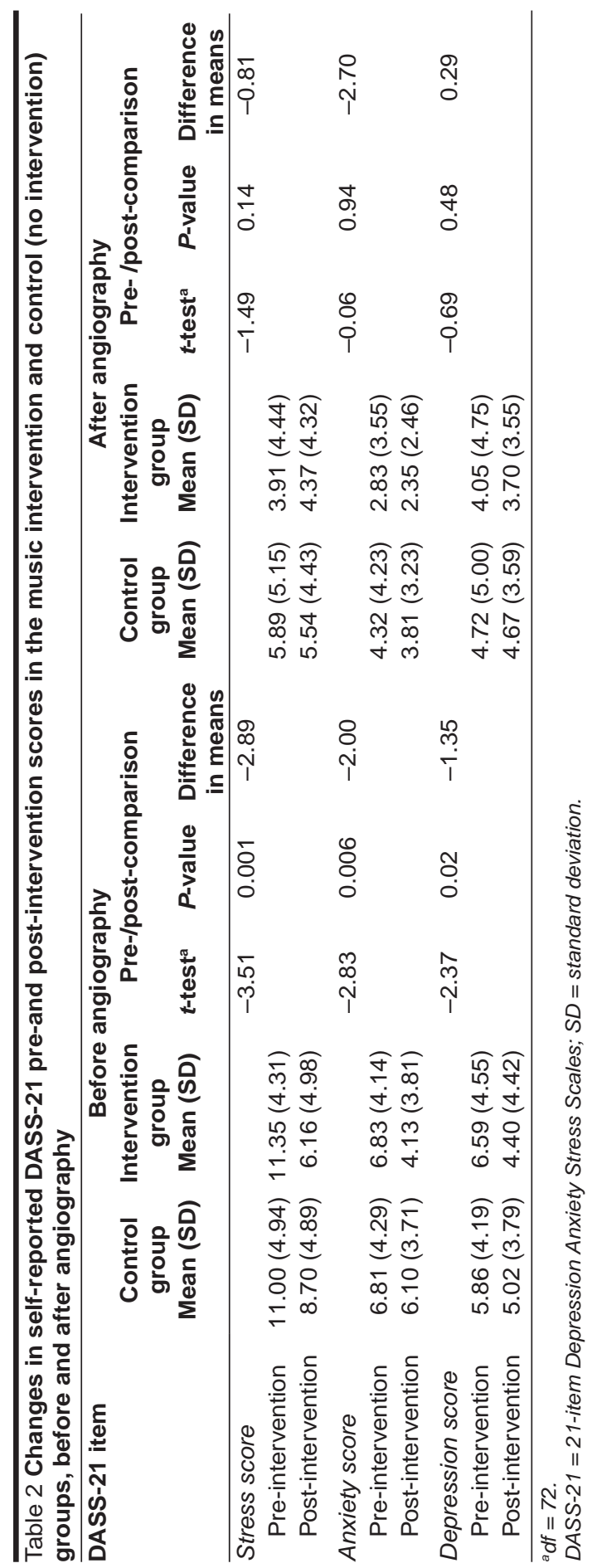

72, $P=0.01)$, anxiety $(t=-2.67$, d.f $=$ $72, P=0.01)$ and depression $(t=-1.9$, $\mathrm{df}=72, P=0.05)$. Also, the groups informed of the angiography results (normal or abnormal reports) had the same stress and anxiety in the study period. Although there was no significant difference between the group receiving normal results and the group receiving abnormal results in the mean scores after angiography for stress $(t=1.92, \mathrm{df}=31$, $P=0.06, n=33)$ and anxiety $(t=1.1$, df $=31, P=0.27, n=33)$, there was a significant difference in depression $(t=$ 2.15 , $\mathrm{df}=31, P=0.04, n=33$ ).

Overall, the findings from both the music and control groups showed that the group that received the music intervention experienced a decrease in stress, anxiety and depression levels before undergoing cardiac angiography, whereas those without music did not. Conversely, after the angiography procedure, no significant differences were apparent between the groups in the 3 measured parameters of the DASS- 21 .

\section{Discussion}

The purpose of this study was to examine the effect of music as a nursing intervention on the levels of anxiety, stress, and depression experienced by patients undergoing a coronary angiographic procedure.

Our results revealed positive outcomes on the differences between the pre-intervention-post-intervention DASS-21 scores for stress, anxiety and depression, completed prior to coronary angiography. The music intervention group had significantly lower scores on the post-intervention DASS-21 administered before angiography as compared 
with the control group. However, no significant differences were found with either the music intervention or the control group after angiography. On the basis of these findings, listening to 20 minutes of relaxing music prior to angiography resulted in less stress, anxiety and depression in patients undergoing angiography than did scheduled bed rest.

Prior to angiography patients are especially prone to anxiety or even panic caused by signing a consent form for the procedure, the knowledge of possible progression to surgery if serious coronary artery disease is detected and the lack of sufficient information about the planned procedure. Before the coronary angiographic procedure and the intervention, the levels of anxiety, stress and depression were high in both groups. However, after the intervention these levels decreased in the experimental group, with a significant difference in the amount of the decrease. This randomized clinical trial has provided evidence that, before coronary angiography, the patients who listened to music in a relaxed atmosphere reported less stress, anxiety and depression when compared with those who did not listen to music.

Our findings support previous studies on this topic that having an angiographic procedure is a stressful event for many patients. Numerous studies have shown that music is effective in reducing stress or anxiety $[2,6,8,15-20]$. McCaffrey and Locsin presented the use of music listening as an effective, noninvasive intervention designed to assist nurses in creating a healing environment to promote health and well-being. The study demonstrated the effectiveness of music in reducing pain, decreasing anxiety and increasing relaxation [2]. Winter et al. demonstrated music's ability to reduce stress and anxiety in patients in the surgical holding area [6]. Good et al., assessing the effects of music and jaw relaxation on post- operative pain relief in 500 patients, found that listening to music could decrease arthritis pain in women [15]. Listening to music has been effective in reducing pre-operative anxiety [16] and reducing stress [17]. The impact of music on anxiety associated with diagnostic procedures has also been examined by Hamel [8] and Vahhabi [18], who demonstrated that patients waiting for their cardiac catheterization benefited from music therapy. Dubois et al. concluded that music during bronchoscopy is a simple and inexpensive nonpharmacological way to improve patients; comfort [19]. Palakanis et al. reported that patients who listened to self-selected music tapes during flexible sigmoidoscopy experienced a reduction in anxiety level [20].

Our study was not able to demonstrate that music was effective in reducing anxiety, stress and depression of patients after cardiac angiography. After the procedure, these levels decreased in both groups, with no significant difference in the amount of the decrease. This might be related to the fact that the successful completion of an invasive procedure is stress reducing in itself. Bally et al. also found that a patientcontrolled music intervention had no effect on post-procedural anxiety [1]. McRee et al. failed to demonstrate that massage and music therapy can decrease post-operative anxiety scores. The decreased level of anxiety in the control group could have been related to a sense of relief that the surgery was finished [21].

As indicated by our results, listening to relaxing music, a noninvasive and inexpensive intervention, can allay patients' anxiety, stress and depression. These results have implications for nursing practice. Nurses must have an understanding of the need to provide nonpharmacological, costeffective approaches to improving patients' surgical experiences and pre-operative and

المجلة الصحية لشرق المتو سط، منظمة الصحة العالمية، المجلد الخامس عشر، العدد ب، 9 +. 
post-operative outcomes. If nurses had the knowledge and ability to use music therapy to alleviate patients' mood, this would increase the capability of the stress management team to decrease stress, anxiety and depression. The nurse can assist the anxious and depressed client by implementing interventions that maintain or restore a sense of calm.

A limitation of this study is that we did not evaluate the patients' preferences for music; ideally, patients should be invited to choose the music that they wish to listen to. Furthermore, our study was based on the use of a questionnaire and we therefore did not attempt to measure levels of anxiety, stress and depression during the procedure itself. Further research is needed to cover these limitations.

\section{Conclusions}

According to the results of this study, listening to music significantly lowers anxiety, stress and depression of patients before undergoing an invasive procedure. Patients undergoing angiography who listened to 20-minute relaxing music tape had a marked reduction in anxiety, stress and depression. Because music is noninvasive and free of side-effects, it can be used as an effective nursing intervention for those undergoing coronary angiography procedures.

\section{References}

1. Bally $\mathrm{K}$ et al. Effects of patient-controlled music therapy during coronary angiography. Critical care nursing, 2003, 23(2):50-5.

2. McCaffrey R, Locsin RC. Music listening as a nursing intervention: a symphony of practice. Holistic nursing practice, 2002, 16(3):70-7.

3. Pratt RR. Art, dance, and music therapy. Physical medicine and rehabilitation clinics of North America, 2004, 15(4):82784.

4. Nickel AK et al. Outcome research in music therapy-a step on the long road to an evidence-based treatment. Annals of the New York Academy of Sciences, 2005, 1060:283-93.

5. Rogers ME. Nursing: a science of unitary human beings. In: Riehl-Sisca JP, ed. Conceptual models for nursing practice, 3rd ed. Norwalk, Connecticut, Appleton and Lange, 1980:181-8.

6. Winter MJ, Paskin S, Baker T. Music reduces stress and anxiety of patients in the surgical holding area. Journal of post anesthesia nursing, 1994, 9(6):340-3.

7. Brunges $\mathrm{N}$, Aringe $\mathrm{G}$. Music therapy for reducing surgical anxiety. AORN journal, 2003, 78(5):816-8.

8. Hamel WJ. The effects of music intervention on anxiety in the patient waiting for cardiac catheterization. Intensive and critical care nursing, 2001, 17(5):279-85.

9. Svansdottir HB, Snaedal J. Music therapy in moderate and severe dementia of Alzheimer's type: a case-control study, International psychogeriatrics, 2006, 18(4):613-21.

10. Sendelbach SE et al. Effects of music therapy on physiological and psychological outcomes for patients undergoing cardiac surgery. Journal of cardiovascular nursing, 2006, 21(3):194-200.

11. Cevasco AM, Kennedy R, Generally NR. Comparison of movement-to-music, rhythm activities, and competitive games on depression, stress, anxiety, and anger of females in substance abuse reha- 
bilitation. Journal of music therapy, 2005, 42(1):64-80.

12. Gallagher LM et al. The clinical effects of music therapy in palliative medicine. Supportive care in cancer, 2006, 14(8):85966.

13. Antony MA et al. Psychometric properties of the 42-item and 21-item versions of the Depression Anxiety Stress Scale in clinical groups and a community sample. Psychological assessment, 1998, 10(2):176-81.

14. Ortiz J. The Tao of music: sound psychology. York Beach, Massachusetts, Samuel Weiser Inc., 1998.

15. Good M et al. Relief of postoperative pain with jaw relaxation, music and their combination. Pain, 1999, 81:163-72.

16. Augustin P, Hains A. Effect of music on ambulatory surgery patients' preoperative anxiety. AORN journal, 1996, 63(4):750-8.
17. Burns JL et al. The effects of different types of music on perceived and physiological measures of stress. Journal of music therapy, 2002, 39:101-16.

18. Vahhabi SY. The effect of music therapy and relaxation on anxiety of patients with cardiovascular diseases [MSc thesis]. Tehran, Department of Nursing, Iran University of Medical Sciences, 1998.

19. Dubois JM, Bartter T, Pratter MR. Music improves patient comfort level during outpatient bronchoscopy. Chest, 1995, 108(1):129-30.

20. Palakanis KC et al. Effect of music therapy on state anxiety in patients undergoing flexible sigmoidoscopy. Diseases of the colon and rectum, 1994, 37(5):478-81.

21. McRee LD, Noble S, Pasvogel A. Using massage and music therapy to improve postoperative outcomes. AORN journal, 2003, 78(3):433-47.

\section{Cardiovascular diseases}

The Eastern Mediterranean Region is facing a growing epidemic of cardiovascular diseases provoked by an ageing population and socioeconomic changes.

The WHO programme on cardiovascular diseases aims to develop global strategies to reduce the incidence, morbidity and mortality of cardiovascular diseases by:

- effectively reducing cardiovascular disease risk factors and their determinants

- developing cost-effective and equitable health care innovations for management of cardiovascular diseases

- monitoring trends of cardiovascular diseases and their risk factors

Further information can be found at: http://www.emro.who.int/ncd/ cardiovascular_diseases.htm 